\title{
Common variation in $N C A N$, a risk factor for bipolar disorder and schizophrenia, influences local cortical folding in schizophrenia
}

\author{
C. C. Schultz ${ }^{1 *}$, T. W. Mühleisen ${ }^{2,3,4}$, I. Nenadic ${ }^{1}$, K. Koch $^{1,5}$, G. Wagner ${ }^{1}$, C. Schachtzabel ${ }^{1}$, \\ F. Siedek ${ }^{2,3}$, M. M. Nöthen ${ }^{2,3,6}$, M. Rietschel ${ }^{7}$, T. Deufel ${ }^{8}$, M. Kiehntopf ${ }^{8}$, S. Cichon ${ }^{2,3,4,9}$, \\ J. R. Reichenbach ${ }^{10}$, H. Sauer ${ }^{1}$ and R. G. M. Schlösser ${ }^{1}$ \\ ${ }^{1}$ Department of Psychiatry and Psychotherapy, Jena University Hospital, Germany \\ ${ }^{2}$ Institute of Human Genetics, University of Bonn, Germany \\ ${ }^{3}$ Department of Genomics, Life and Brain Centre, University of Bonn, Germany \\ ${ }^{4}$ Institute of Neuroscience and Medicine (INM-1), Research Centre Juelich, Germany \\ ${ }^{5}$ Department of Neuroradiology, Klinikum rechts der Isar, Technische Universität München, Germany \\ ${ }^{6}$ German Centre for Neurodegenerative Diseases (DZNE), Bonn, Germany \\ ${ }^{7}$ Department of Genetic Epidemiology in Psychiatry, Central Institute of Mental Health, Medical Faculty Mannheim/Heidelberg University, \\ Germany \\ ${ }^{8}$ Department of Clinical Chemistry and Laboratory Diagnostics, Jena University Hospital, Germany \\ ${ }^{9}$ Division of Medical Genetics, University of Basel, Switzerland \\ ${ }^{10}$ Medical Physics Group, Institute for Diagnostic and Interventional Radiology I, Jena University Hospital, Germany
}

Background. Recent studies have provided strong evidence that variation in the gene neurocan (NCAN, rs1064395) is a common risk factor for bipolar disorder (BD) and schizophrenia. However, the possible relevance of NCAN variation to disease mechanisms in the human brain has not yet been explored. Thus, to identify a putative pathomechanism, we tested whether the risk allele has an influence on cortical thickness and folding in a well-characterized sample of patients with schizophrenia and healthy controls.

Method. Sixty-three patients and 65 controls underwent T1-weighted magnetic resonance imaging (MRI) and were genotyped for the single nucleotide polymorphism (SNP) rs1064395. Folding and thickness were analysed on a nodeby-node basis using a surface-based approach (FreeSurfer).

Results. In patients, NCAN risk status (defined by AA and AG carriers) was found to be associated with higher folding in the right lateral occipital region and at a trend level for the left dorsolateral prefrontal cortex. Controls did not show any association $(p>0.05)$. For cortical thickness, there was no significant effect in either patients or controls.

Conclusions. This study is the first to describe an effect of the NCAN risk variant on brain structure. Our data show that the NCAN risk allele influences cortical folding in the occipital and prefrontal cortex, which may establish disease susceptibility during neurodevelopment. The findings suggest that NCAN is involved in visual processing and topdown cognitive functioning. Both major cognitive processes are known to be disturbed in schizophrenia. Moreover, our study reveals new evidence for a specific genetic influence on local cortical folding in schizophrenia.

Received 26 August 2012; Revised 16 May 2013; Accepted 23 May 2013; First published online 24 June 2013

Key words: Cerebral cortex, hypergyrification, SNP, V1, V2, visual system.

\section{Introduction}

Schizophrenia is a severe mental illness that affects $1 \%$ of the population worldwide. Among the major psychiatric disorders, schizophrenia shows one of the highest estimates of heritability, ranging between $60 \%$

* Address for correspondence: C. C. Schultz, M.D., Department of Psychiatry and Psychotherapy, Jena University Hospital,

Philosophenweg 3, 07740 Jena, Germany.

(Email: christoph.schultz@med.uni-jena.de)

t These authors contributed equally to this work. and 90\% (Nöthen et al. 2010). However, the neurobiological abnormalities determined by this genetic risk are poorly understood. In a recent genome-wide association study (GWAS) and in a follow-up study (Cichon et al. 2011), we found strong statistical evidence that the single nucleotide polymorphism (SNP) rs1064395 in the $3^{\prime}$ untranslated region of the neurocan (NCAN) gene on chromosome 19p13.11 is a risk factor for bipolar disorder (BD). In view of formal genetic and molecular genetic evidence that BD and schizophrenia share some of their risk factors, we performed a subsequent association study and identified that this 
common variation is also a risk factor for schizophrenia (Mühleisen et al. 2012). Both studies found that the A allele of rs1064395 is the risk-mediating allele. These results suggest that the SNP rs1064395 influences risk to a broader psychosis phenotype. In the next step, imaging studies are necessary to test the hypothesis that the NCAN risk allele mediates pathophysiologically relevant changes in the brain.

NCAN, formerly termed CSPG3, encodes neurocan, a brain-specific chondroitin sulfate proteoglycan (CSPG) of the lectican family (Prange et al. 1998). Recent analyses of mRNA expression patterns in mice and humans suggest an important role for NCAN in the developing mammalian brain (Cichon et al. 2011; see also BrainSpan: Atlas of the Developing Human Brain; www.brainspan.org). Neurocan molecules are mainly expressed by reactive astrocytes, but also by neurons (Karetko \& Skangiel-Kramska, 2009). Neurocan interacts with cell surface molecules, such as neural cell adhesion molecule (NCAM), L1/neuronglia (L1/Ng)-CAM, transient axonal glycoprotein-1 (TAG-1)/axonin-1 and an N-cadherin-binding N-acetylgalactosaminyl phosphoryltransferase (GalNAcPTase) (Rauch et al. 2001). These features enable neurocan to participate in the modulation of cell adhesion and migration. Furthermore, neurocan and other lecticans are thought of as 'organizers' of the extracellular matrix (ECM) in the central nervous system (Yamaguchi, 2000). From embryogenesis to early postnatal stages, neurocan is one of the predominant lecticans in the brain ECM whereas, later in life, other members of this protein family prevail (Frischknecht \& Seidenbecher, 2008; Karetko \& Skangiel-Kramska, 2009). Characterization of NCAN double-knockout mice demonstrated impaired pre-pulse inhibition (Miró et al. 2012), an intermediate phenotype for schizophrenia and also for BD (Thaker, 2008). The affected mice also showed higher exploratory and overall locomotor activity. Accordingly, in patients with schizophrenia and BD, the risk allele was strongly associated with the symptom dimension overactivity, providing further support for an association between NCAN and psychosis pathophysiology (Miró et al. 2012). Despite these strong molecular and behavioural data, the possible relevance of NCAN variation for disease mechanisms in the human brain has not yet been explored.

In the past few years, imaging genetics has emerged as a promising approach in neuropsychiatric research. It enables identification and characterization of genetic variants that influence brain structure and function underlying normal and abnormal biological pathways (Esslinger et al. 2009; Erk et al. 2010; Schultz et al. 2011; Stein et al. 2012). In the present study, we investigated the SNP rs1064395 for a potential effect on cortical morphology using a clinically well-characterized sample of 63 patients with a DSM-IV diagnosis of schizophrenia and 65 healthy controls, all of German origin. We measured two parameters for cortical shape (cortical thickness and cortical folding) and subdivided the patients and controls according to their NCAN risk status. Cortical thickness is assumed to approximate the distance between the pial surface (outer surface) and the border between the grey and white matter (inner surface) of the cortex. As major parts of the formation of gyri (and sulci) take place in the third prenatal trimester (White \& Hilgetag, 2011), cortical folding can be regarded as a sensitive marker for aberrations in neurodevelopment. Alterations in cortical thickness (Kuperberg et al. 2003; Narr et al. 2005a,b; Fornito et al. 2008; Nesvåg et al. 2008; Schultz et al. $2010 b, c$ ) and cortical folding (McIntosh et al. 2009; Schultz et al. 2010a; Palaniyappan et al. 2011) have been associated repeatedly with schizophrenia. Additionally, both structural measures are highly heritable (Rogers et al. 2010; Winkler et al. 2010) and are therefore suitable intermediate phenotypes for our approach.

Carrying the minor allele A of rs1064395 has been shown to confer a risk effect that increases disease susceptibility and, conversely, carrying the G-allele can be assumed to establish a protective effect (Cichon et al. 2011; Mühleisen et al. 2012). We therefore hypothesized that carriers of the genotypes AA and AG exhibit aberrant cortical thickness and/or cortical folding in comparison to carriers of the genotype GG.

\section{Method}

\section{Subjects}

We studied 63 patients with schizophrenia and 65 controls. All participants were right-handed (Annett, 1967). Diagnoses based on the SCID were established by a clinical psychiatrist (I.N.) and confirmed by two independent psychiatrists (R.G.M.S. and C.C.S.). All patients met DSM-IV criteria for schizophrenia and had no second psychiatric diagnosis. Of the 63 patients, 58 were diagnosed as paranoid, two as undifferentiated, two as disorganized and one as catatonic subtype of schizophrenia according to DSM-IV. They were on stable medication, mostly with secondgeneration antipsychotics.

Healthy controls were screened for major medical, neurological and psychiatric history. None of the controls had a current psychiatric disorder, or a history of psychiatric disorder, and none had first-degree relatives with a psychiatric disorder according to DSM-IV. Exclusion criteria for all participants were neurological disease or damage, or medical disorders potentially influencing neurocognitive function. Ancestry was assigned to patients and controls on the basis of 
Table 1. Demographic and clinical data

\begin{tabular}{llll}
\hline \multicolumn{3}{l}{ Genetic groups } & \\
\cline { 2 - 3 } & GG & AA/AG & $p$ \\
\hline Healthy controls & & & \\
$\quad n$ & 51 & 14 & \\
$\quad$ Age (years), mean (S.D.) & $26.7(6.8)$ & $25.6(8.1)$ & 0.593 \\
Patients & & & \\
$n$ & 49 & 14 & \\
Age (years), mean (s.D.) & $29.4(10.0)$ & $26.9(10.0)$ & 0.410 \\
PANSS total, mean (S.D.) & $69.2(26.5)$ & $73.9(28.7)$ & 0.565 \\
PANSS positive, & $15.8(7.3)$ & $19.3(8.3)$ & 0.150 \\
$\quad$ mean (s.D.) & & & \\
$\quad$ PANSS negative, & $18.1(6.9)$ & $17.4(10.2)$ & 0.788 \\
$\quad$ mean (s.D.) & & & \\
$\quad$ CPZE, mean (s.D.) & $479.8(419.1)$ & $283.3(208.1)$ & 0.122 \\
& & &
\end{tabular}

PANSS, Positive and Negative Syndrome Scale (Kay et al. 1987); CPZE, chlorpromazine equivalents; S.D., standard deviation.

Participants were grouped according to their NCAN risk status, that is homozygous and heterozygous risk genotype $(\mathrm{AA}+\mathrm{AG})$ versus the homozygous non-risk genotype (GG) of the single nucleotide polymorphism (SNP) rs1064395. There were no significant differences with regard to age and gender between the resulting genotype groups ( $p$ values $>0.190$ ).

$p$ values resulting from a two-sample $t$ test.

self-reported ancestry. All participants were of German origin. None of the subjects were consanguineous. All participants gave written informed consent to the study, which was approved by the Ethics Committee of Friedrich-Schiller University. Sociodemographic and psychopathological data are given in Table 1.

\section{Magnetic resonance imaging (MRI)}

MRI acquisition

We acquired high-resolution anatomical T1-weighted MRI scans in a 1.5-T Siemens Magnetom Vision whole-body system (Erlangen, Germany) using a three-dimensional spoiled gradient echo sequence: 1-mm-thick sagittal slices with repetition time $(\mathrm{TR})=$ $15 \mathrm{~ms}$, echo time $(\mathrm{TE})=5 \mathrm{~ms}$, flip angle $=30^{\circ}$, field of view $(\mathrm{FOV})=256 \mathrm{~mm} \times 256 \mathrm{~mm}$, matrix $=256 \times 256$, number of sagittal slices $=192$. All scans were inspected for motion artefacts and a neuroradiologist confirmed the absence of gross pathological findings.

\section{$M R$ scan processing and calculation of cortical shape measures}

We used the FreeSurfer software package (version 4.0.5; http://surfer.nmr.mgh.harvard.edu; Dale et al.
1999; Fischl et al. 1999) for image processing and for thickness and folding analyses. Image processing comprised the removal of non-brain tissue, transformation to Talairach-like space and segmentation of grey/white matter tissue. The white/grey matter boundary was tessellated and topological defects were corrected automatically. After intensity normalization, transition of the grey/white matter and pial boundary was identified by detecting the greatest shift in intensity through surface deformation. The entire cortex of each participant was then inspected visually and any inaccuracies in segmentation were edited manually.

\section{Computation of cortical thickness}

Cortical thickness was computed by finding the shortest distance between a given point (node of vertices) on the estimated pial surface and the grey/white matter boundary and vice versa and averaging these two values (Fischl \& Dale, 2000). As the cortical maps generated were not restricted to the voxel resolution of the original data, they were capable of detecting submillimetre differences between diagnostic groups. This automated approach of cortical thickness measurement has been validated against manual measurements in schizophrenia (Kuperberg et al. 2003).

\section{Computation of cortical folding}

Absolute mean curvature represents a very reliable local measure for cortical folding alterations, allowing a fine-grained comparison of cortical folding covering the entire cortex (Gaser et al. 2006; Luders et al. 2006). Absolute mean curvature of the pial surface was calculated as described by Schultz et al. (2010a) for approximately 150000 nodes in each hemisphere of the brain.

\section{Genotyping and determination of subgroups according to the risk status}

For the patients, rs1064395 genotypes were extracted from a genome-wide data set that had been genotyped and quality controlled in the study by Rietschel et al. (2011). For the controls, lymphocyte DNA was isolated from venous blood samples using standard methods. To target SNP rs1064395 a primer pair was designed. Amplicons were generated using standard polymerase chain reaction (PCR) conditions. These were then sequenced using the Sanger method and a 3130XL Genetic Analyzer (Applied Biosystems, USA). Electropherograms were analysed by two independent investigators using SeqMan II (DNAStar, USA).

Depending on the NCAN risk status, patients and controls were divided into subgroups resulting in 
Table 2. Results of the cluster analysis for cortical folding in patients with schizophrenia

\begin{tabular}{|c|c|c|c|c|c|c|}
\hline \multirow[b]{2}{*}{ Cortex area } & \multirow[b]{2}{*}{ Size $\left(\mathrm{mm}^{2}\right)$} & \multicolumn{3}{|c|}{ Talairach coordinates } & \multirow[b]{2}{*}{ CWP } & \multirow[b]{2}{*}{$p$ value (nominal) } \\
\hline & & $\mathrm{x}$ & $\mathrm{y}$ & $\mathrm{z}$ & & \\
\hline Right lateral occipital & 623.1 & 25.3 & -95.0 & 3.6 & 0.032 & $1.00 \times 10^{-4}$ \\
\hline Left dorsolateral prefrontal & 526.4 & -7.1 & 24.4 & 52.9 & 0.073 & $6.10 \times 10^{-5}$ \\
\hline
\end{tabular}

CWP, Cluster-wise probability.

CWP (corrected for multiple testing) resulting from the cluster analysis in each cortical hemisphere; nominal (uncorrected) $p$ values resulting from Student's $t$ tests comparing the average cortical folding values at the identified anatomical clusters (as illustrated in Fig. 1).

two genotype groups for each diagnostic group, that is $2 \times(\mathrm{AA}+\mathrm{AG})$ and $2 \times \mathrm{GG}$, for statistical analyses. We compared risk allele (A) carriers with non-risk allele carriers in patients and controls separately, that is controls: AA+ AG versus GG; patients: AA+AG versus GG. There were no significant differences with regard to age and gender between the resulting genotype groups ( $p$ values $>0.190)$.

\section{Statistical analyses}

\section{Statistical cortical maps}

Cortical thickness and cortical folding measurements at each vertex of the subjects' surface were mapped onto a common spherical coordinate system using a spherical transformation. Maps were smoothed using a Gaussian kernel of $10 \mathrm{~mm}$. A general linear model (GLM) controlling for the effect of age was used to estimate differences in cortical thickness and cortical folding at each node. The GLM is based on an ANCOVA approach. Right and left hemispheres were tested separately.

\section{Monte Carlo simulation and clustering}

For correction of multiple comparisons, a Monte Carlo simulation (10000 iterations) and a cluster analysis were performed to identify contiguous clusters of significant cortical thickness and cortical folding differences between the two genotype groups for each analysis $(p<0.05)$. The simulation and clustering approach is based on the AlphaSim algorithm (Ward, 2000).

\section{Results}

\section{Effect of NCAN risk status on the two cortical shape measures}

Schizophrenia patients carrying the homozygous and heterozygous risk genotypes (AA, AG) exhibited significantly higher cortical folding covering parts of the right visual cortex (V1 and V2 areas) than patients with the GG genotype (CWP $=0.032$; Table 2, Fig. $1 b)$. A statistical trend $(\mathrm{CWP}=0.073)$ was found for the left dorsolateral prefrontal cortical folding in the schizophrenia risk carriers (Table 2; Fig. 1a). Extraction of the cortical folding values from these clusters demonstrated comparable highly significant nominal $p$ values: $p=1 \times 10^{-4}$ for the lateral occipital cluster and $p=6.10 \times 10^{-5}$ for the prefrontal cluster.

No effect of NCAN risk status on cortical folding was observed in the controls. For cortical thickness, no effect of the risk variant was found, either in the patients or in the controls.

\section{Genotype $\times$ diagnosis interaction}

To test for differing effects of the rs1064395 genotype on diagnosis, we additionally performed a genotype $\times$ diagnosis interaction analysis as in prior imaging genetics studies (Prata et al. 2009), using the same statistical parameters as defined for the initial analyses (Monte Carlo simulation, clustering). We found a significant genotype $\times$ diagnosis interaction for cortical folding in the right superior parietal cortex, that is the influence of the NCAN variant on cortical folding was significantly stronger in patients (in the direction of a higher cortical folding in risk carriers) than in controls.

\section{Comparison of cortical thickness and folding between patients and controls}

We analysed the main effect of diagnosis on cortical thickness and folding post hoc using the same statistical conditions as defined for the primary analyses. Patients showed significant cortical thinning in several cortical areas including the left superior, middle and inferior temporal cortex, left inferior parietal, right inferior frontal, orbitofrontal, right superior, middle and inferior temporal cortex, in line with previous 


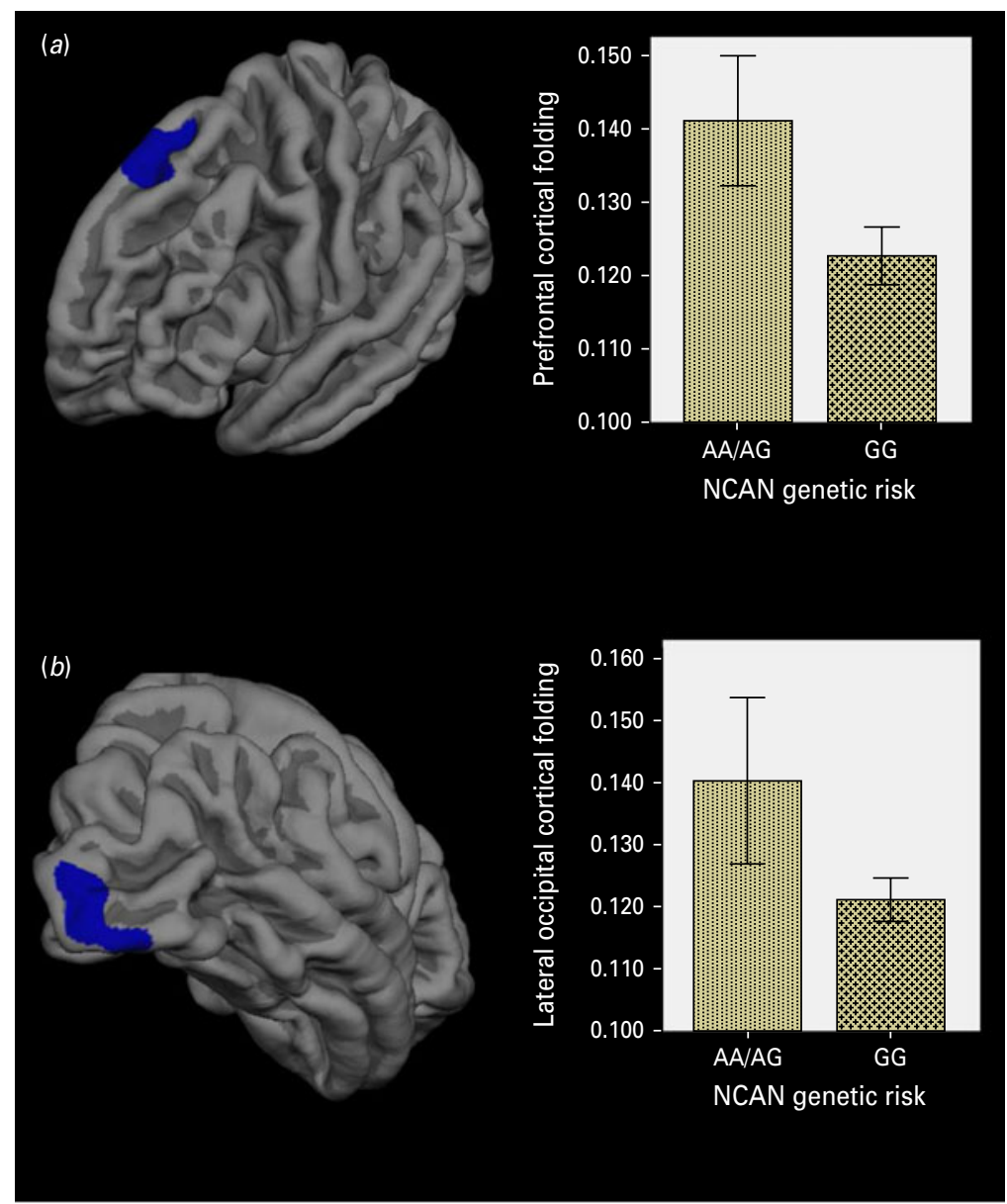

Fig. 1. Effect of the neocan $(N C A N)$ risk status on cortical folding in patients with schizophrenia. Statistical maps show the identified anatomical clusters (coloured in blue) encompassing regions in $(a)$ the left prefrontal and $(b)$ the right lateral occipital cortex. Bar diagrams illustrate the folding differences between risk allele carriers (AA+AG) compared to non-risk allele carriers (GG) of the single nucleotide polymorphism (SNP) rs1064395. Mean cortical folding values extracted from the anatomical clusters between risk and non-risk carriers. Error bars indicate 95\% confidence interval.

findings (Kuperberg et al. 2003; Narr et al. 2005a,b; Nesvåg et al. 2008; Schultz et al. 2010b,c). We found no significant cortical folding differences between patients and controls.

In a subsequent analysis, we compared cortical thickness and folding only in risk allele carriers using the same statistical parameters as defined for the initial analysis (entire cortex analysis, Monte Carlo Simulation and automated clustering). In patients, we found a significant cortical thinning with the AA/AG genotype compared to controls with the same genotype covering smaller parts of the left inferior and middle temporal region and the right inferior temporal, fusiform and lateral occipital cortex. No significant effects were detected for cortical folding.

\section{Discussion}

The investigated NCAN variant is one of the few genetic risk factors for major psychoses (BD, schizo- phrenia) that has received genome-wide support and robust evidence for replication in follow-up studies. To the best of our knowledge, the present study is the first to characterize the impact of this variant on the cortex structure in humans.

\section{Effect of NCAN variation on occipital and frontal cortical folding}

Our main finding was that cortical folding in association with NCAN risk status was significantly altered in parts of the primary and secondary visual areas (V1, V2) of the right occipital lobe in patients with schizophrenia, but not in the matched controls. Both V1 and V2 are related to early visual processing and deficits for these areas have been reported for schizophrenia (Butler \& Javitt, 2005). Disturbed cortical integration of visual and other sensory inputs is thought to be involved in cognitive disruption in schizophrenia, as suggested by current bottom-up models (Javitt, 
2009). Although the visual cortex in schizophrenia seems to be relatively free from reductions in grey matter volume (Honea et al. 2005), several independent studies of schizophrenia have found alterations of occipital cortical folding (White et al. 2003; Narr et al. 2004; Schultz et al. 2010a, 2013). Hence, the observed association between the NCAN risk variant and disturbed occipital cortex folding suggests a role for NCAN in visual processing. Future studies are warranted to validate and further explore this potential function of NCAN.

Second, we found a strong statistical trend in the left hemisphere for altered dorsolateral prefrontal cortical folding in patients with NCAN risk. Prefrontal dysfunction is thought to be a major constituent of altered cognitive control in schizophrenia (Minzenberg et al. 2009), with crucial functions in higher-level gating and top-down processing (Miller, 2000). Thus, the joint finding of fronto-occipital cortical folding alterations provides indirect support for an integrative model of both higher-order and early sensory processing deficits in the cortex of schizophrenia patients (Silbersweig \& Stern, 1996; Adcock et al. 2009; Hugdhal, 2009; Hahn et al. 2010; Neuhaus et al. 2011; Waters et al. 2012). Moreover, our findings might reflect a potential pathomechanism for an additive disruption of top-down and bottom-up cortical processing associated with schizophrenia.

Third, we found a significantly stronger effect of the genotype on right superior parietal cortical folding in patients compared to controls in the direction of higher cortical folding in risk carriers. Hence, this finding supports the observed effects of the NCAN risk genotype on cortical folding in patients. The superior parietal cortex is known as a crucial structure for the reorganization of information during working memory processing (Koenigs et al. 2009). Disturbed working memory is one of the major pathophysiological features in schizophrenia (Forbes et al. 2009). Both prefrontal and superior parietal dysfunction constitute important elements in the context of disturbed cognitive control and associated altered working memory deficits in schizophrenia (Minzenberg et al. 2009). Thus, our finding of a significant genotype $\times$ diagnosis interaction strengthens the view that NCAN might be involved in altered higher-order cognitive functioning in schizophrenia.

In view of our previous result that NCAN variation is also a common risk factor for BD (Cichon et al. 2011), it is of note that top-down cognitive dysfunction (Hill et al. 2008; Reichenberg et al. 2009) and visual processing deficits (Green et al. 1994; Yeap et al. 2009) are thought to be neurobiological features of both major psychoses. This observation might lead to the conclusion that specific common cognitive features in schizophrenia and BD are based on overlapping genetic risk variants such as NCAN. In view of the recent aetiological discussions about the psychosis spectrum, we are of the opinion that only a convergent integration of genetic, cognitive and neuroimaging features can shed further light on this important issue.

\section{Cortical folding as an intermediate phenotype associated with NCAN variation in schizophrenia}

An important aspect of our study is that the NCAN risk variant demonstrated an association with cortical folding but not with cortical thickness. This observation provides further support for accumulating evidence that specific neuroimaging features can be phenotypically and genetically independent (Panizzon et al. 2009; Winkler et al. 2010). Our data suggest that NCAN might be specifically related to cortical folding rather than cortical thickness. This provides the first genetic evidence for a specific underpinning of localized cortical folding aberrations in schizophrenia.

As suggested by the spatiotemporal gene expression patterns in mice and humans (Cichon et al. 2011), along with the functions of NCAN known to date (Frischknecht \& Seidenbecher, 2008; Karetko \& Skangiel-Kramska, 2009; Miró et al. 2012), the common genetic variant in NCAN most probably exerts its disease-relevant effect on cortex structure when major folding processes (gyrification) take place (White et al. 2003). After the cortical folding pattern has been established, it is largely maintained during life (Armstrong et al. 1991). In line with this, mechanical models of brain development in primates indicate that folding is driven by the formation of corticocortical connections (Hilgetag \& Barbas, 2006), and further animal experiments have demonstrated that early disruption of white matter connections are related to focal hypergyria (Goldman-Rakic, 1980). This view is also supported by a recent study by Dauvermann et al. (2012), who analysed prefrontal gyrification together with functional connectivity. Overall, our results, in conjunction with prior knowledge, indicate that increased prefrontal gyrification might be related to increased short-range and reduced long-range connectivity. Thus, our finding that genetic variation in NCAN is specifically associated with altered cortical folding, a neurodevelopmental cortical marker, fits well with previous molecular and neuroimaging studies.

Based on current knowledge, the question of how NCAN (encoding neurocan) contributes precisely to these neurodevelopmental processes at the molecular level cannot be answered definitively. In humans, NCAN is expressed in many cortical and subcortical regions (see BrainSpan: Atlas of the Developing Human Brain; www.brainspan.org). The expression 
in the cortex peaks during development starts to fall after birth, and decreases continually until the end of life (Human Brain Transcriptome (transcriptome data and associated metadata for the developing and adult human brain, www.hbatlas.org); Johnson et al. 2009; Kang et al. 2011). Therefore, high NCAN expression levels coincide with the maturation of folding and connectivity patterns. This, and its molecular properties as an ECM molecule, enable neurocan to participate in the modulation of cell adhesion and migration processes during corticogenesis. As cortical folding, in addition to the mechanical properties of axonal fibres ('tension-based hypothesis'), is thought to be caused by synergistic effects of cell proliferation and differentiation ('grey matter hypothesis') (Zilles et al. 2013), it seems likely that NCAN proteins are involved in cortical folding. The common genetic variant (SNP rs1064395) that we have analysed in the present study is a risk factor for schizophrenia and also for BD, but has not yet been characterized at the molecular genetic level. Our imaging genetics study provides the first evidence for a potential effect of the risk variant (A allele) on cortex structure. How the variant or another variant in linkage disequilibrium contributes exactly to an aberrant folding in the occipital and frontal regions remains to be elucidated in further follow-up studies.

\section{Limitations}

Cortical folding is regarded as an important anatomical feature in schizophrenia (Mangin et al. 2010). In the present study we demonstrated the influence of NCAN on frontal and occipital cortical folding using an entire cortex approach. However, it cannot be excluded that other regions might be affected using region-of-interest (ROI) approaches. Thus, further studies with independent samples are needed to explore the role of NCAN in disease architecture.

Regarding the comparison of cortical folding between patients and controls, it might be of relevance that the numbers of risk allele carriers in both diagnostic groups were equal. This might explain why we could not detect any folding differences between the diagnostic groups as we demonstrated that the NCAN SNP influences cortical folding in patients.

One further limitation is that, because of the lack of longitudinal data, we cannot provide information about differences with regard to psychosis outcome, which might be influenced by the risk variant in association with the influence on cortical folding. Thus, longitudinal studies on this issue are warranted.

\section{Conclusions}

This is the first study to describe a potential neuroanatomical pathomechanism driven by a NCAN risk variant in schizophrenia patients. In particular, we used a systematic imaging genetics approach across both hemispheres and identified that the risk allele or alleles in linkage disequilibrium with it influence the folding of the occipital and prefrontal lobe in patients but not in controls. This finding indicates a potential role for NCAN in higher-order cognitive functioning and early visual processing. Both major cognitive processes are known to be disturbed in schizophrenia. Our study also provides evidence for a specific genetic underpinning of localized cortical folding aberrations in schizophrenia. This work is a good starting point for future studies, which should further investigate the suggested functional aspects along with the possible role of NCAN variation in brains of patients with BD. In general, we conclude that it might be beneficial to assess cortical folding as an additional intermediate phenotype in future studies of the cortex structure.

\section{Acknowledgements}

This study was supported by the German Federal Ministry of Education and Research (BMBF) grant 01GW0740 and the Interdisciplinary Centre for Clinical Research (IZKF) of the University of Jena.

\section{Declaration of Interest}

None.

\section{References}

Adcock RA, Dale C, Fisher M, Aldebot S, Genevsky A, Simpson GV, Nagarajan S, Vinogradov S (2009). When top-down meets bottom-up: auditory training enhances verbal memory in schizophrenia. Schizophrenia Bulletin 35, 1132-1141.

Annett M (1967). The binomial distribution of right, mixed and left handedness. Quarterly Journal of Experimental Psychology 19, 327-333.

Armstrong E, Schleicher A, Omran H, Curtis M, Zilles K (1991). The ontogeny of human gyrification. Cerebral Cortex 5, 56-63.

Butler PD, Javitt DC (2005). Early-stage visual processing deficits in schizophrenia. Current Opinion in Psychiatry 18, 151-157.

Cichon S, Mühleisen TW, Degenhardt FA, Mattheisen M, Miró X, Strohmaier J, Steffens M, Meesters C, Herms S, Weingarten $M$, Priebe L, Haenisch B, Alexander $M$, Vollmer J, Breuer R, Schmäl C, Tessmann P, Moebus S, Wichmann HE, Schreiber S, Müller-Myhsok B, Lucae S, Jamain S, Leboyer M, Bellivier F, Etain B, Henry C, Kahn JP, Heath S; Bipolar Disorder Genome Study (BiGS) Consortium, Hamshere M, O'Donovan MC, Owen MJ, Craddock N, Schwarz M, Vedder H, Kammerer-Ciernioch J, Reif A, Sasse J, Bauer M, Hautzinger M, Wright A, Mitchell PB, Schofield PR, 
Montgomery GW, Medland SE, Gordon SD, Martin NG, Gustafsson O, Andreassen O, Djurovic S, Sigurdsson E, Steinberg S, Stefansson $H$, Stefansson $K$, Kapur-Pojskic L, Oruc L, Rivas F, Mayoral F, Chuchalin A, Babadjanova G, Tiganov AS, Pantelejeva G, Abramova LI, Grigoroiu-Serbanescu M, Diaconu CC, Czerski PM, Hauser J, Zimmer A, Lathrop M, Schulze TG, Wienker TF, Schumacher J, Maier W, Propping P, Rietschel M, Nöthen MM (2011). Genome-wide association study identifies genetic variation in neurocan as a susceptibility factor for bipolar disorder. American Journal of Human Genetics 88, 372-381.

Dale AM, Fischl B, Sereno MI (1999). Cortical surface-based analysis. I. Segmentation and surface reconstruction. Neurolmage 9, 179-194.

Dauvermann MR, Mukherjee P, Moorhead WT, Stanfield AC, Fusar-Poli P, Lawrie SM, Whalley HC (2012). Relationship between gyrification and functional connectivity of the prefrontal cortex in subjects at high genetic risk of schizophrenia. Current Pharmaceutical Design 18, 434-442.

Erk S, Meyer-Lindenberg A, Schnell K, Opitz von Boberfeld C, Esslinger C, Kirsch P, Grimm O, Arnold C, Haddad L, Witt SH, Cichon S, Nöthen MM, Rietschel M, Walter H (2010). Brain function in carriers of a genome-wide supported bipolar disorder variant. Archives of General Psychiatry 67, 803-811.

Esslinger C, Walter H, Kirsch P, Erk S, Schnell K, Arnold C, Haddad L, Mier D, Opitz von Boberfeld C, Raab K, Witt SH, Rietschel M, Cichon S, Meyer-Lindenberg A (2009). Neural mechanisms of a genome-wide supported psychosis variant. Science 324, 605.

Fischl B, Dale AM (2000). Measuring the thickness of the human cerebral cortex from magnetic resonance images. Proceedings of the National Academy of Sciences USA 97, 11050-11055.

Fischl B, Sereno MI, Dale AM (1999). Cortical surface-based analysis. II: Inflation, flattening, and a surface-based coordinate system. Neurolmage 9, 195-207.

Forbes NF, Carrick LA, McIntosh AM, Lawrie SM (2009). Working memory in schizophrenia: a meta-analysis. Psychological Medicine 39, 889-905.

Fornito A, Yücel M, Wood SJ, Adamson C, Velakoulis D, Saling MM, McGorry PD, Pantelis C (2008). Surface-based morphometry of the anterior cingulate cortex in first episode schizophrenia. Human Brain Mapping 29, 478-489.

Frischknecht R, Seidenbecher CI (2008). The crosstalk of hyaluronan-based extracellular matrix and synapses. Neuron Glia Biology 4, 249-257.

Gaser C, Luders E, Thompson PM, Lee AD, Dutton RA, Geaga JA, Hayashi KM, Bellugi U, Galaburda AM, Korenberg JR, Mills DL, Toga AW, Reiss A (2006). Increased local gyrification mapped in Williams syndrome. NeuroImage 33, 46-54.

Goldman-Rakic PS (1980). Morphological consequences of prenatal injury to the primate brain. Progress in Brain Research 53, 1-19.

Green MF, Nuechterlein KH, Mintz J (1994). Backward masking in schizophrenia and mania. II. Specifying the visual channels. Archives of General Psychiatry 51, 945-951.

Hahn B, Robinson BM, Kaiser ST, Harvey AN, Beck VM, Leonard CJ, Kappenman ES, Luck SJ, Gold JM (2010). Failure of schizophrenia patients to overcome salient distractors during working memory encoding. Biological Psychiatry 68, 603-609.

Hilgetag CC, Barbas H (2006). Role of mechanical factors in the morphology of the primate cerebral cortex. PLoS Computational Biology 2, e22.

Hill SK, Harris MSH, Herbener ES, Pavuluri M, Sweeney JA (2008). Neurocognitive allied phenotypes for schizophrenia and bipolar disorder. Schizophrenia Bulletin 34, 743-759.

Honea R, Crow TJ, Passingham D, Mackay CE (2005). Regional deficits in brain volume in schizophrenia: a meta-analysis of voxel-based morphometry studies. American Journal of Psychiatry 162, 2233-2245.

Hugdahl K (2009). 'Hearing voices': auditory hallucinations as failure of top-down control of bottom-up perceptual processes. Scandinavian Journal of Psychology 50, 553-560.

Javitt DC (2009). When doors of perception close: bottom-up models of disrupted cognition in schizophrenia. Annual Review of Clinical Psychology 5, 249-275.

Johnson MB, Kawasawa YI, Mason CE, Krsnik Z, Coppola G, Bogdanović D, Geschwind DH, Mane SM, State MW, Sestan N (2009). Functional and evolutionary insights into human brain development through global transcriptome analysis. Neuron 62, 494-509.

Kang HJ, Kawasawa YI, Cheng F, Zhu Y, Xu X, Li M, Sousa AM, Pletikos M, Meyer KA, Sedmak G, Guennel T, Shin Y, Johnson MB, Krsnik Z, Mayer S, Fertuzinhos S, Umlauf S, Lisgo SN, Vortmeyer A, Weinberger DR, Mane S, Hyde TM, Huttner A, Reimers M, Kleinman JE, Sestan N (2011). Spatio-temporal transcriptome of the human brain. Nature 478, 483-489.

Karetko M, Skangiel-Kramska J (2009). Diverse functions of perineuronal nets. Acta Neurobiologiae Experimentalis 69, 564-577.

Kay SR, Fiszbein A, Opler LA (1987). The positive and negative syndrome scale (PANSS) for schizophrenia. Schizophrenia Bulletin 13, 261-276.

Koenigs M, Barbey AK, Postle BR, Grafman J (2009). Superior parietal cortex is critical for the manipulation of information in working memory. Journal of Neuroscience 29, 14980-14986.

Kuperberg GR, Broome MR, McGuire PK, David AS, Eddy M, Ozawa F, Goff D, West WC, Williams SC, van der Kouwe AJ, Salat DH, Dale AM, Fischl B (2003). Regionally localized thinning of the cerebral cortex in schizophrenia. Archives of General Psychiatry 60, 878-888.

Luders E, Thompson PM, Narr KL, Toga AW, Jancke L, Gaser C (2006). A curvature-based approach to estimate local gyrification on the cortical surface. NeuroImage 29, 1224-1230.

Mangin JF, Jouvent E, Cachia A (2010). In-vivo measurement of cortical morphology: means and meanings. Current Opinion in Neurology 23, 359-367. 
McIntosh AM, Moorhead TWJ, McKirdy J, Hall J, Sussmann JED, Stanfield AC, Harris JM, Johnstone EC, Lawrie SM (2009). Prefrontal gyral folding and its cognitive correlates in bipolar disorder and schizophrenia. Acta Psychiatrica Scandinavica 119, 192-198.

Miller EK (2000). The prefrontal cortex and cognitive control. Nature Reviews Neuroscience 1, 59-65.

Minzenberg MJ, Laird AR, Thelen S, Carter CS, Glahn DC (2009). Meta-analysis of 41 functional neuroimaging studies of executive function in schizophrenia. Archives of General Psychiatry 66, 811-822.

Miró X, Meier S, Dreisow ML, Frank J, Strohmaier J, Breuer R, Schmäl C, Albayram Ö, Pardo-Olmedilla MT, Mühleisen TW, Degenhardt FA, Mattheisen M, Reinhard I, Bilkei-Gorzo A, Cichon S, Seidenbecher C, Rietschel M, Nöthen MM, Zimmer A (2012).

Studies in humans and mice implicate neurocan in the etiology of mania. American Journal of Psychiatry 169, 982-990.

Mühleisen TW, Mattheisen M, Strohmaier J, Degenhardt F, Priebe L, Schultz CC, Breuer R, Meier S, Hoffmann P; GROUP Investigators, Rivandeneira $F$, Hofman A, Uitterlinden AG, Moebus S, Gieger C, Emeny R, Ladwig KH, Wichmann HE, Schwarz M, Kammerer-Ciernioch J, Schlösser RG, Nenadic I, Sauer H, Mössner R, Maier W, Rujescu D, Lange C, Ophoff RA, Schulze TG, Rietschel M, Nöthen MM, Cichon S (2012). Association between schizophrenia and common variation in neurocan (NCAN), a genetic risk factor for bipolar disorder. Schizophrenia Research 138, 69-73.

Narr KL, Bilder RM, Kim S, Thompson PM, Szeszko P, Robinson D, Luders E, Toga AW (2004). Abnormal gyral complexity in first-episode schizophrenia. Biological Psychiatry 55, 859-867.

Narr KL, Bilder RM, Toga AW, Woods RP, Rex DE, Szeszko PR, Robinson D, Sevy S, Gunduz-Bruce H, Wang YP, DeLuca H, Thompson PM (2005a). Mapping cortical thickness and gray matter concentration in first episode schizophrenia. Cerebral Cortex 15, 708-719.

Narr KL, Toga AW, Szeszko P, Thompson PM, Woods RP, Robinson D, Sevy S, Wang Y, Schrock K, Bilder RM (2005b). Cortical thinning in cingulate and occipital cortices in first episode schizophrenia. Biological Psychiatry $58,32-40$.

Nesvåg R, Lawyer G, Varnäs K, Fjell AM, Walhovd KB, Frigessi A, Jönsson EG, Agartz I (2008). Regional thinning of the cerebral cortex in schizophrenia: effects of diagnosis, age and antipsychotic medication. Schizophrenia Research 98, $16-28$.

Neuhaus AH, Karl C, Hahn E, Trempler NR, Opgen-Rhein C, Urbanek C, Hahn C, Ta TM, Dettling M (2011). Dissection of early bottom-up and top-down deficits during visual attention in schizophrenia. Clinical Neurophysiology 122, 90-98.

Nöthen MM, Nieratschker V, Cichon S, Rietschel M (2010). New findings in the genetics of major psychoses. Dialogues in Clinical Neuroscience 12, 85-93.

Palaniyappan L, Mallikarjun P, Joseph V, White TP, Liddle PF (2011). Folding of the prefrontal cortex in schizophrenia: regional differences in gyrification. Biological Psychiatry 69, 974-979.

Panizzon MS, Fennema-Notestine C, Eyler LT, Jernigan TL, Prom-Wormley E, Neale M, Neale M, Jacobson $K$, Lyons MJ, Grant MD, Franz CE, Xian $H$, Tsuang $M$, Fischl B, Seidman L, Dale A, Kremen WS (2009). Distinct genetic influences on cortical surface area and cortical thickness. Cerebral Cortex 19, 2728-2735.

Prange CK, Pennacchio LA, Lieuallen K, Fan W, Lennon GG (1998). Characterization of the human neurocan gene, CSPG3. Gene 221, 199-205.

Prata DP, Mechelli A, Picchioni MM, Fu CH, Toulopoulou T, Bramon E, Walshe M, Murray RM, Collier DA, McGuire P (2009). Altered effect of dopamine transporter 3'UTR VNTR genotype on prefrontal and striatal function in schizophrenia. Archives of General Psychiatry 66, 1162-72.

Rauch U, Feng K, Zhou XH (2001). Neurocan: a brain chondroitin sulfate proteoglycan. Cellular and Molecular Life Sciences 58, 1842-1856.

Reichenberg A, Harvey PD, Bowie CR, Mojtabai R, Rabinowitz J, Heaton RK, Bromet E (2009).

Neuropsychological function and dysfunction in schizophrenia and psychotic affective disorders. Schizophrenia Bulletin 35, 1022-1029.

Rietschel M, Mattheisen M, Degenhardt F; Genetic Risk and Outcome in Psychosis (GROUP Investigators), Mühleisen TW, Kirsch P, Esslinger C, Herms S, Demontis D, Steffens M, Strohmaier J, Haenisch B, Breuer R, Czerski PM, Giegling I, Strengman E, Schmael C, Mors O, Mortensen PB, Hougaard DM, Ørntoft T, Kapelski P, Priebe L, Basmanav FF, Forstner AJ, Hoffman P, Meier S, Nikitopoulos J, Moebus S, Alexander M, Mössner R, Wichmann H-E, Schreiber S, Rivandeneira F, Hofman A, Uitterlinden AG, Wienker TF, Schumacher J, Hauser J, Maier W, Cantor RM, Erk S, Schulze TG; SGENE-plus Consortium, Craddock N, Owen MJ, O'Donovan MC, Børglum AD, Rujescu D, Walter H, Meyer-Lindenberg A, Nöthen NM, Ophoff RA, Cichon S (2011). Association between genetic variation in a region on chromosome 11 and schizophrenia in large samples from Europe. Molecular Psychiatry 17, 906-917.

Rogers J, Kochunov P, Zilles K, Shelledy W, Lancaster J, Thompson P, Duggirala R, Blangero J, Fox PT, Glahn DC (2010). On the genetic architecture of cortical folding and brain volume in primates. NeuroImage 53, 1103-1108.

Schultz CC, Koch K, Wagner G, Roebel M, Nenadic I, Gaser C, Schachtzabel C, Reichenbach JR, Sauer H, Schlösser RG (2010a). Increased parahippocampal and lingual gyrification in first-episode schizophrenia. Schizophrenia Research 123, 137-144.

Schultz CC, Koch K, Wagner G, Roebel M, Nenadic I, Schachtzabel C, Reichenbach JR, Sauer H, Schlösser RG (2010b). Complex pattern of cortical thinning in schizophrenia: results from an automated surface based analysis of cortical thickness. Psychiatry Research 182, 134-140. 
Schultz CC, Koch K, Wagner G, Roebel M, Schachtzabel C, Gaser C, Nenadic I, Reichenbach JR, Sauer H, Schlösser RG (2010c). Reduced cortical thickness in first episode schizophrenia. Schizophrenia Research 116, 204-209.

Schultz CC, Nenadic I, Koch K, Wagner G, Roebel M, Schachtzabel C, Mühleisen TW, Nöthen MM, Cichon S, Deufel T, Kiehntopf M, Rietschel M, Reichenbach JR, Sauer H, Schlösser RG (2011). Reduced cortical thickness is associated with the glutamatergic regulatory gene risk variant DAOA Arg30Lys in schizophrenia. Neuropsychopharmacology 36, 1747-1753.

Schultz CC, Wagner G, Koch K, Gaser C, Roebel M, Schachtzabel C, Nenadic I, Reichenbach JR, Sauer H, Schlösser RG (2013). The visual cortex in schizophrenia: alterations of gyrification rather than cortical thickness - a combined cortical shape analysis. Brain Structure and Function 218, 51-58.

Silbersweig D, Stern E (1996). Functional neuroimaging of hallucinations in schizophrenia: toward an integration of bottom-up and top-down approaches. Molecular Psychiatry 1, 367-375.

Stein JL, Medland SE, Vasquez AA, Hibar DP, Senstad RE, Winkler AM, Toro R, Appel K, Bartecek R, Bergmann Ø, Bernard M, Brown AA, Cannon DM, Chakravarty MM, Christoforou A, Domin M, Grimm O, Hollinshead M, Holmes AJ, Homuth G, Hottenga JJ, Langan C, Lopez LM, Hansell NK, Hwang KS, Kim S, Laje G, Lee PH, Liu X, Loth E, Lourdusamy A, Mattingsdal M, Mohnke S, Maniega SM, Nho K, Nugent AC, O'Brien C, Papmeyer M, Pütz B, Ramasamy A, Rasmussen J, Rijpkema M, Risacher SL, Roddey JC, Rose EJ, Ryten M, Shen L, Sprooten E, Strengman E, Teumer A, Trabzuni D, Turner J, van Eijk K, van Erp TG, van Tol MJ, Wittfeld K, Wolf C, Woudstra S, Aleman A, Alhusaini S, Almasy L, Binder EB, Brohawn DG, Cantor RM, Carless MA, Corvin A, Czisch M, Curran JE, Davies G, de Almeida MA, Delanty N, Depondt C, Duggirala R, Dyer TD, Erk S, Fagerness J, Fox PT, Freimer NB, Gill M, Göring HH, Hagler DJ, Hoehn D, Holsboer F, Hoogman M, Hosten N, Jahanshad N, Johnson MP, Kasperaviciute D, Kent JW Jr., Kochunov P, Lancaster JL, Lawrie SM, Liewald DC, Mandl R, Matarin M, Mattheisen M, Meisenzahl E, Melle I, Moses EK, Mühleisen TW, Nauck M, Nöthen MM, Olvera RL, Pandolfo M, Pike GB, Puls R, Reinvang I, Rentería ME, Rietschel M, Roffman JL, Royle NA, Rujescu D, Savitz J, Schnack HG, Schnell K, Seiferth N, Smith C, Steen VM, Valdés Hernández MC, Van den Heuvel $M$, van der Wee NJ, Van Haren NE, Veltman JA, Völzke H, Walker R, Westlye LT, Whelan CD, Agartz I, Boomsma DI, Cavalleri GL, Dale AM, Djurovic S, Drevets WC, Hagoort P, Hall J, Heinz A, Jack CR Jr., Foroud TM, Le Hellard S, Macciardi F, Montgomery GW, Poline JB, Porteous DJ, Sisodiya SM, Starr JM, Sussmann J, Toga AW, Veltman DJ, Walter H,
Weiner MW; Alzheimer's Disease Neuroimaging Initiative; EPIGEN Consortium; IMAGEN Consortium; Saguenay Youth Study Group, Bis JC, Ikram MA, Smith AV, Gudnason V, Tzourio C, Vernooij MW, Launer LJ, DeCarli C, Seshadri S; Cohorts for Heart and Aging Research in Genomic Epidemiology Consortium, Andreassen OA, Apostolova LG, Bastin ME, Blangero J, Brunner HG, Buckner RL, Cichon S, Coppola G, de Zubicaray GI, Deary IJ, Donohoe G, de Geus EJ, Espeseth T, Fernández G, Glahn DC, Grabe HJ, Hardy J, Hulshoff Pol HE, Jenkinson M, Kahn RS, McDonald C, McIntosh AM, McMahon FJ, McMahon KL, Meyer-Lindenberg A, Morris DW, Müller-Myhsok B, Nichols TE, Ophoff RA, Paus T, Pausova Z, Penninx BW, Potkin SG, Sämann PG, Saykin AJ, Schumann G, Smoller JW, Wardlaw JM, Weale ME, Martin NG, Franke B, Wright MJ, Thompson PM; Enhancing Neuro Imaging Genetics through Meta-Analysis Consortium (2012). Identification of common variants associated with human hippocampal and intracranial volumes. Nature Genetics 44, 552-561.

Thaker GK (2008). Neurophysiological endophenotypes across bipolar and schizophrenia psychosis. Schizophrenia Bulletin 34, 760-773.

Ward BD (2000). Simultaneous inference for fMRI data. Biophysics Research Institute, Medical College of Wisconsin. (http://afni.nimh.nih.gov/pub/dist/doc/manual/AlphaSim. pdf).

Waters F, Allen P, Aleman A, Fernyhough C, Woodward TS, Badcock JC, Barkus E, Johns L, Varese F, Menon M, Vercammen A, Larøi F (2012). Auditory hallucinations in schizophrenia and nonschizophrenia populations: a review and integrated model of cognitive mechanisms. Schizophrenia Bulletin 38, 683-793.

White T, Andreasen NC, Nopoulos P, Magnotta V (2003). Gyrification abnormalities in childhood- and adolescent-onset schizophrenia. Biological Psychiatry 54, 418-426.

White T, Hilgetag CC (2011). Gyrification and neural connectivity in schizophrenia. Development and Psychopathology 23, 339-352.

Winkler AM, Kochunov P, Blangero J, Almasy L, Zilles K, Fox PT, Duggirala R, Glahn DC (2010). Cortical thickness or grey matter volume? The importance of selecting the phenotype for imaging genetics studies. NeuroImage 53, 1135-1146.

Yamaguchi Y (2000). Lecticans: organizers of the brain extracellular matrix. Cellular and Molecular Life Sciences 57, 276-289.

Yeap S, Kelly SP, Reilly RB, Thakore JH, Foxe JJ (2009). Visual sensory processing deficits in patients with bipolar disorder revealed through high-density electrical mapping Journal of Psychiatry and Neuroscience 34, 459-464.

Zilles K, Palomero-Gallagher N, Amunts K (2013). Development of cortical folding during evolution and ontogeny. Trends in Neuroscience 36, 275-284. 